\title{
High Serum Uric Acid Was a Risk Factor for Incident Asthma: An Open Cohort Study
}

This article was published in the following Dove Press journal:

Risk Management and Healthcare Policy

\section{Haixia Wang \\ Yuanmin Jia \\ Mo Yi \\ Yizhang Li \\ Ou Chen}

School of Nursing, Cheeloo College of Medicine, Shandong University, Jinan 2500I2, Shandong, People's Republic of China
Correspondence: Ou Chen School of Nursing, Cheeloo College of Medicine, Shandong University, Jinan 2500 I2, Shandong, People's Republic of China

Tel +86 I599099 I I8I

Email chenou@sdu.edu.cn
Background: Several cross-sectional studies have suggested an association between SUA and asthma. However, few studies have investigated this relationship longitudinally. Although SUA is an independent risk factor for chronic kidney disease and cardiovascular diseases, its contribution to incident asthma remains uncertain.

Objective: To determine whether a high SUA was a risk factor for adult incident asthma. Methods: By using health care data from the Shandong multicenter health check-up, 76,369 participants, aged 20 to 79 years, were identified who had an SUA determination with a mean follow-up period of $3.73 \pm 2.21$ years. Multivariate modeling employed Cox proportional hazards models to verify the association between SUA and incident asthma by adjusting age, BMI, smoking habits, drinking habits, and asthma-like diseases.

Results: A total of 51,389 individuals were included in the analysis. Cut-off values of SUA able to discriminate asthma status were identified by means of maximally selected rank statistics in the whole participants $(\geq 376.80 \mathrm{umol} / \mathrm{L})$, women $(\geq 314.45 \mathrm{umol} / \mathrm{L})$, and men ( $\geq 376.80$ umol/L). Multivariate Cox regression analyses adjusted for covariates (age, body mass index (BMI), smoking habit, drinking habit, and asthma-like disease) identified an independent association between SUA and incident asthma in the whole participants (hazard ratio (HR) 2.92, 95\% confidence intervals (CI), 1.76-4.48, $\mathrm{P}=0.00$ ) and men (HR 3.02, 95\% CI $1.70-5.39, \mathrm{P}=0.00)$, but not in women.

Conclusion: The results of the current study confirmed that high SUA was an independent risk factor for incident asthma after adjustment of potential covariates and suggested that a cut-off value related to incident asthma could be identified only in men.

Keywords: cut-off value, asthma, gender, serum uric acid, risk factor

Asthma is one of the most common non-communicable and chronic respiratory diseases in children and adults, and affects approximately 334 million people worldwide. ${ }^{1}$ It has a significant impact on those affected, particularly when taking a patient's quality of life, absenteeism, and substantial economic burden into account. ${ }^{2-4}$ However, there is no treatment available to cure asthma. ${ }^{5}$ Therefore, it is particularly important to find the risk factors of asthma to prevent the occurrence of asthma.

Uric acid (UA) is the final product of nucleic acid metabolism and is the most abundant molecule with antioxidant properties found in human blood serum. ${ }^{6,7}$ Serum uric acid (SUA) is measured frequently in the primary care setting to assess renal function, diagnose gout, and monitor drug response. ${ }^{8,9}$ Recently, SUA has been suggested to have an association with hypertension, metabolic syndrome, and cardiovascular diseases. ${ }^{10-12}$ However, the relationship between SUA and respiratory 
disorders remained unclear. Studies have shown that UA was a known trigger for acute neutrophilic inflammation and an inflammatory mediator of allergic asthma. ${ }^{13,14}$ Besides, SUA levels increased at the onset of asthma exacerbation, and had a negative impact on spirometric pulmonary functions in asthmatics. $^{15,16}$ However, at present, whether the level of SUA affects the occurrence of incident asthma is uncertain.

Some studies supported an independent association between both SUA and hypertension, as well as cardiovascular disease, and it was also clear that these associations were stronger in women. ${ }^{17}$ However, whether there are gender differences in the relationship between SUA and asthma has not been investigated by researchers.

For the specific purpose of the analysis shown herein, we conducted an open cohort study to explore the relationship between SUA and incident asthma both men and women. We hypothesized that a higher SUA was associated with a higher risk of incident asthma.

\section{Methods}

\section{Study Design}

The study was an open prospective cohort study that examined the relationship between SUA at baseline and incident asthma with a mean follow-up period of 3.73 \pm 2.21 years. The study used health care data from over 20 health management centers in Shandong Province from January 2004 to December 2015 to identify participants with incident asthma, and the study design is shown in Figure 1. The study was approved by the Institutional Ethical Committee, School of Nursing, Cheeloo College of Medicine, Shandong University (2003-R-036). The study was in compliance with the Declaration of Helsinki for clinical research. All participants provided written informed consent before participating in the study.

The database was built on a regional basis by collecting data on individuals from representative cohorts having

\section{Study Design}

\section{Shandong multi-center health check-up longitudinal study from 2004-2015}

\section{Inclusion criteria:}

(1) aged $\geq 20$ years;

(2) have regular physical examination (once a year) more than three times during follow-up;

(3) free from asthma at baseline;

(4) informed consent to participate voluntarily.

Exclusion criteria:

(1) missing indicators related to serum uric acid.

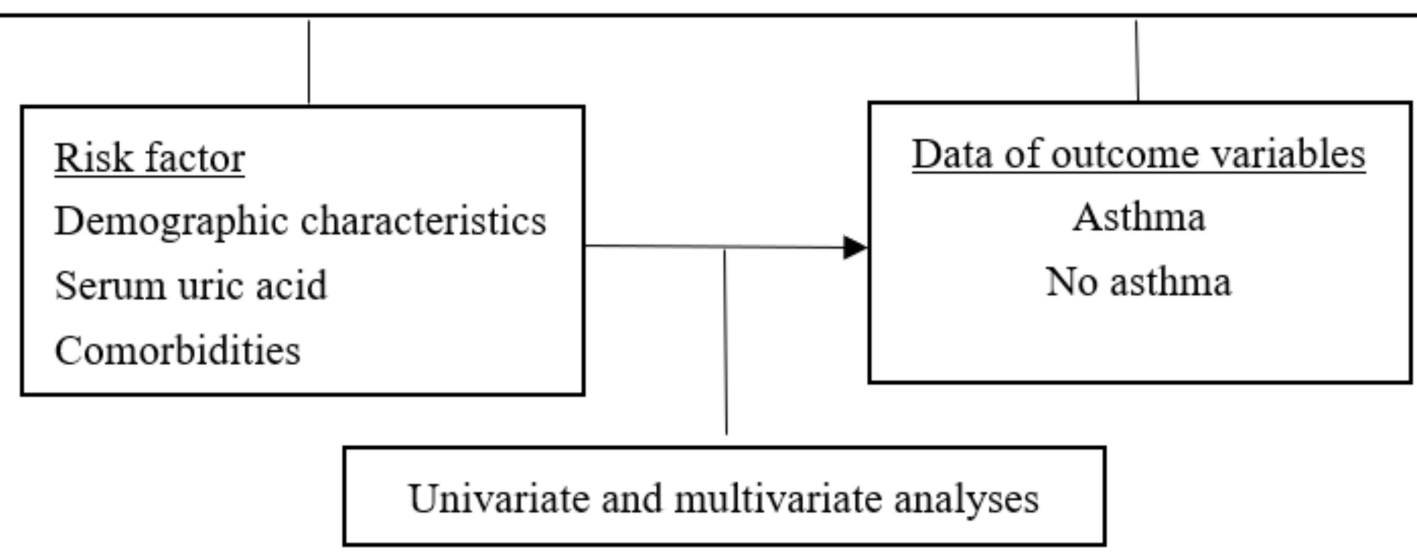

Figure I Study design. 
SUA measurement and complete information about several variables. For all individuals, a standardized set of items was recorded, including demographics, smoking habits, drinking habits, height, weight, and asthma-like diseases (rhinitis, nasal polyps, pneumonia, bronchitis, pulmonary infection, bronchiectasis, and chronic obstructive pulmonary disease (COPD)).

\section{Inclusion and Exclusion Criteria}

The inclusion criteria were as follows: (1) aged $\geq 20$ years; (2) had regular physical examination (once a year) over three times during follow-up; (3) free from asthma at baseline; and (4) individuals who provided informed consent to participate voluntarily; Exclusion criteria: participants had an undetermined baseline SUA.

\section{Diagnostic Criteria for Asthma}

The diagnostic criteria for asthma were according to the guidelines for Asthma Section, Respiratory Disease Branch, Chinese Medical Association. ${ }^{18}$

\section{Statistical Analysis}

The R package version 4.0.2 and IBM SPSS Statistics 24 were used for statistical analysis.

\section{General Description}

Continuous variables were reported as mean \pm standard deviation or median (interquartile range [IQR]), and categorical variables as frequency (percentage). Betweengroup comparisons were performed using the $t$-test or Wilcoxon rank-sum test for continuous variables and using the chi-square test for categorical variables.

\section{Preliminary Cox Analysis}

SUA as a continuous item was used as the independent variable in Cox analyses both in the whole participants and separately in men and women, and age, BMI, smoking habits, drinking habits, and asthma-like disease as possible covariates. HR with $95 \%$ CI were produced. The null hypothesis was rejected for values of $P$ less than 0.05 .

\section{Univariate Cut-off Values}

We estimated the optimal cut-off value of SUA for predicting the occurrence of incident asthma using maximally selected rank statistics. ${ }^{19}$ This cut-off value was optimal for separation into high and low levels of SUA. Statistically significant differences using this cut-off value were examined using $P$ values.

\section{Kaplan-Meier Curves}

In the whole participants and separately in women and men, the cumulative risk of SUA cut-off points and asthma incidence over time was calculated using the KaplanMeier cumulative hazard function, and Log rank tests were used to evaluate the differences between groups.

\section{Validation of the Cut-off Values}

The cut-off values of SUA identified by means of the maximally selected rank statistics were tested in two ways: they were used separately as independent variables in multivariate Cox analyses adjusted for the covariates, the occurrence of incident asthma as the dependent variable. The analysis was performed on the whole participants as well as in men and women. The corresponding HR and $95 \% \mathrm{CI}$ were obtained; Besides, considering the low incidence of asthma in this study, we also performed the Poisson regression model to verify the reliability of the results.

\section{Results}

\section{Descriptive Statistics}

Among the 76,368 original participants at the baseline examination in this study, 51,389 eligible subjects were included finally. In total, 88 eligible subjects developed incident asthma during the follow-up, including 36 women (40.91\%) and 52 men (59.09\%) (Figure 2).

General characteristics of the 51,389 individuals are shown and also stratified by gender in Table 1. During 176,643 person-years of follow-up, 88 participants experienced incident asthma: 52 events occurred in men during 108,175 person-years of follow-up and the crude incidence density of asthma was 0.48 per 1000 person-years; 36 events occurred in women during 68,468 person-years of follow-up, and the crude incidence density of asthma was 0.53 per 1000 person-years.

\section{Multivariate Analysis}

Preliminary Cox models having incident asthma as a dependent variable showed that SUA as a continuous variable was associated with incident asthma in the whole participants and men (HR 1.00, 95\% CI 1.00-1.01, $P=0.01$ ) (HR 1.01, 95\% CI 1.00-1.01 $P=0.00$ ); however, SUA as a continuous item was rejected in women from the model (HR 1.00, 95\% CI 0.99-1.01 $P=0.56$ ). This result was consistent with the result that SUA was used as a continuous variable without adjusting for covariates (Men: HR 1.01, 95\% CI 1.00-1.01 $P=0.00$; Women: HR 


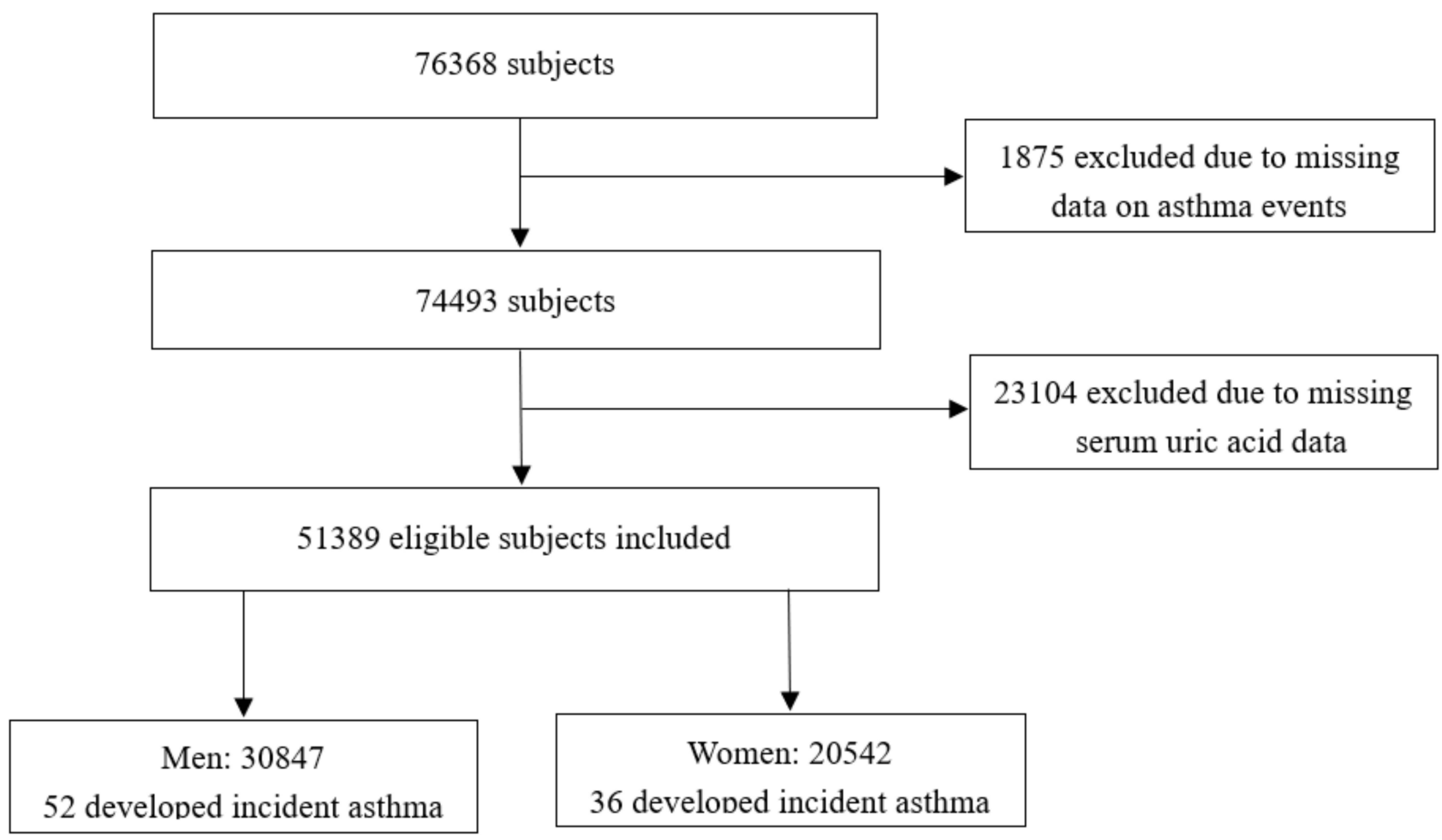

Figure 2 Overview of study participant.

1.00, 95\% CI 0.99-1.01 $P=0.09$; Total: HR 1.00, 95\% CI 1.00-1.01 $P=0$. 02) (Table 2). We also used the Poisson regression model for analysis, and the analysis results were similar to the Cox proportional hazard model analysis (Supplementary Table 1).

\section{Search for Cut-off Values}

Maximally selected rank statistics furnished plausible univariate cut-off value of SUA for incident asthma among men, women, and whole participants, and the corresponding $P$ value of less than 0.02 (Men: 376.80umol/L; Women: $314.45 \mathrm{umol} / \mathrm{L}$; Total: $376.80 \mathrm{umol} / \mathrm{L})$. The result is shown in Figure 3.

\section{Confirmation of the Cut-off Value}

In multivariate Cox analyses adjusted for age, gender, BMI, smoking habits, drinking habits, and asthma-like diseases, the cut-off value of SUA for incident asthma was accepted in the model in men and all participants. (Men: HR 3.02, CI 1.70-5.39, $\mathrm{P}=0.00$; Total: HR 2.92, CI 1.76-4.84, $\mathrm{P}=0.00$ ), however, the cut-off value of SUA was rejected in the women (HR 1.75, 95\% CI 0.78-3.96 P=0.18) (Table 3). We also used the Poisson regression model for analysis, and the analysis results were similar in the Cox proportional hazard model analysis (Supplementary Table 2).

\section{Application of the Confirmed Cut-off Values}

Kaplan-Meier curves are shown in Figure 4. The curves of individuals having SUA cutoff or less and SUA more than cut-off were separate without adjusting for covariates in men, women, and all participants $(P<0.05)$.

\section{Discussions}

In the open cohort study of 51,389 individuals, we found that high SUA was an independent risk factor for incident asthma after adjusting for potential covariates, and also identified the theoretical optimal cut-off of SUA level for incident asthma. ( $\geq 376.80 \mathrm{umol} / \mathrm{L})$

Concerning gender, the literature showed that a difference exists between women and men for SUA. ${ }^{20}$ Interestingly, we divided all participants according to gender, and SUA was $28.20 \%$ lower in women than in men. We generally obtained cut-off values from a population including both genders that be of no help. Because a patient can only be male or female in clinical practice. This is why we think it is 
Table I Characteristics of 5I,389 Participants Included in the Study

\begin{tabular}{|c|c|c|c|c|c|c|c|c|c|}
\hline \multirow[t]{2}{*}{ Characteristics } & \multicolumn{3}{|c|}{ Men $(30,847)$} & \multicolumn{3}{|c|}{ Women $(20,542)$} & \multicolumn{3}{|c|}{ Total Participants $(n=51,389)$} \\
\hline & $\begin{array}{l}\text { Asthma } \\
(n=52)\end{array}$ & $\begin{array}{l}\text { Control } \\
(n=30,795)\end{array}$ & $P$ & $\begin{array}{l}\text { Asthma } \\
(n=36)\end{array}$ & $\begin{array}{l}\text { Control } \\
(n=20,506)\end{array}$ & $\mathbf{P}$ & $\begin{array}{l}\text { Asthma } \\
(n=88)\end{array}$ & $\begin{array}{l}\text { Control } \\
(n=51,301)\end{array}$ & $\mathbf{P}$ \\
\hline Age, years, mean $\pm S D$ & $47.25 \pm 11.68$ & $40.73 \pm|2.6|$ & $0.00 *$ & $47.89 \pm 12.52$ & $41.54 \pm 13.39$ & $0.00 *$ & $47.51 \pm 11.97$ & $41.05 \pm 12.94$ & $0.00 *$ \\
\hline $\begin{array}{l}\text { Age, years, no.(\%) } \\
20-30 \\
30-40 \\
40-50 \\
50-60 \\
>60\end{array}$ & $\begin{array}{l}2(3.85) \\
17(32.69) \\
13(25.00) \\
12(23.08) \\
8(15.38)\end{array}$ & $\begin{array}{l}7706(25.02) \\
8764(28.4 I) \\
7862(25.53) \\
3952(12.83) \\
25 I I(8.15)\end{array}$ & $0.00 *$ & $\begin{array}{l}3(8.33) \\
6(16.67) \\
14(38.89) \\
7(19.44) \\
6(16.67)\end{array}$ & $\begin{array}{l}5275(25.72) \\
5150(25.11) \\
5026(24.5 I) \\
2997(14.62) \\
2058(10.04)\end{array}$ & $0.00 *$ & $\begin{array}{l}5(5.68) \\
23(26.14) \\
27(30.68) \\
19(21.59) \\
14(15.91)\end{array}$ & $\begin{array}{l}12,986(25.3 \mid) \\
13,937(27.17) \\
12,9 \mid 5(25.17) \\
6968(13.58) \\
4583(8.93)\end{array}$ & $0.00 *$ \\
\hline $\mathrm{BMI}, \mathrm{kg} / \mathrm{m}^{2}$, mean $\pm \mathrm{SD}$ & $25.35 \pm 3.50$ & $25.67 \pm 15.46$ & 0.90 & $24.60 \pm 3.01$ & $23.68 \pm 5.09$ & 0.09 & $25.04 \pm 3.31$ & $24.88 \pm 12.44$ & 0.90 \\
\hline $\begin{array}{l}\text { BMI, } \mathrm{kg} / \mathrm{m}^{2}, \text { no.(\%) } \\
\quad<18.5 \\
18.5-23.9 \\
24.0-27.9 \\
>28.0\end{array}$ & $\begin{array}{l}1(1.92) \\
20(38.46) \\
20(38.46) \\
11(21.15)\end{array}$ & $\begin{array}{l}430(1.40) \\
8781(28.51) \\
14,855(48.24) \\
6729(21.85)\end{array}$ & 0.82 & $\begin{array}{l}0(0.00) \\
14(38.89) \\
15(41.67) \\
7(19.44)\end{array}$ & $\begin{array}{l}1205(5.88) \\
9436(46.02) \\
7839(39.23) \\
2026(9.88)\end{array}$ & 0.12 & $\begin{array}{l}I(1.14) \\
34(38.64) \\
35(39.77) \\
18(20.45)\end{array}$ & $\begin{array}{l}1636(3.19) \\
18,251(35.58) \\
22,729(44.31) \\
8773(17.10)\end{array}$ & 0.50 \\
\hline $\begin{array}{l}\text { Drinking status } \\
\text { Smoking status }\end{array}$ & $\begin{array}{l}21 \text { (40.38) } \\
17(32.69)\end{array}$ & $\begin{array}{l}70 I I(22.77) \\
5667(18.40)\end{array}$ & $\begin{array}{l}0.01 * \\
0.00 *\end{array}$ & $\begin{array}{l}0(0.00) \\
0(0.00)\end{array}$ & $\begin{array}{l}42(0.20) \\
32(0.16)\end{array}$ & $\begin{array}{l}1 \\
1\end{array}$ & $\begin{array}{l}21(23.86) \\
17(19.32)\end{array}$ & $\begin{array}{l}7053(13.75) \\
5699(11.11)\end{array}$ & $\begin{array}{l}0.01 * \\
0.01 *\end{array}$ \\
\hline $\begin{array}{l}\text { Respiratory diseases } \\
\text { Rhinitis } \\
\text { Nasal polyps } \\
\text { Pulmonary infection } \\
\text { Pneumonia } \\
\text { Bronchitis } \\
\text { COPD } \\
\text { Bronchiectasis }\end{array}$ & $\begin{array}{l}1(1.92) \\
2(1.92) \\
1(1.92) \\
8(13.46) \\
8(15.38) \\
6(13.46) \\
1(1.92)\end{array}$ & $\begin{array}{l}101(0.33) \\
44(0.14) \\
122(0.40) \\
294(0.95) \\
320(1.04) \\
75(0.24) \\
37(0.12)\end{array}$ & $\begin{array}{l}0.20 \\
0.00^{*} \\
0.11 \\
0.00^{*} \\
0.00^{*} \\
0.0{ }^{*} \\
0.00^{*}\end{array}$ & $\begin{array}{l}0(0.00) \\
0(0.00) \\
1(5.26) \\
7(18.42) \\
10(26.32) \\
4(7.89) \\
0(0.00)\end{array}$ & $\begin{array}{l}32(0.16) \\
13(0.06) \\
92(0.45) \\
210(1.02) \\
253(1.23) \\
20(0.10) \\
22(0.11)\end{array}$ & $\begin{array}{l}1 \\
1 \\
0.04 * \\
0.00 * \\
0.00 * \\
0.00 * \\
1\end{array}$ & $\begin{array}{l}1(1.14) \\
2(2.27) \\
2(2.27) \\
15(17.05) \\
18(20.45) \\
10(11.36) \\
1(1.14)\end{array}$ & $\begin{array}{l}133(0.26) \\
57(0.11) \\
214(0.42) \\
504(0.98) \\
573(1.12) \\
95(0.19) \\
59(0.12)\end{array}$ & $\begin{array}{l}0.11 \\
0.00^{*} \\
0.01 * \\
0.00^{*} \\
0.00^{*} \\
0.00^{*} \\
0.01 *\end{array}$ \\
\hline
\end{tabular}

Note: $* \mathrm{P}<0.05 /$ Invalid data.

Abbreviations: BMI, body mass index; COPD, chronic obstructive pulmonary disease.

Table 2 Cox Models for Incident Asthma Using Serum Uric Acid as a Continuous Independent Variable

\begin{tabular}{|c|c|c|c|c|c|c|c|c|c|c|c|c|}
\hline \multirow{4}{*}{$\begin{array}{l}\text { Independent Variables } \\
\text { Unadjusted covariates } \\
\text { SUA }\end{array}$} & \multicolumn{4}{|l|}{ Men } & \multicolumn{4}{|c|}{ Women } & \multicolumn{4}{|c|}{ Total } \\
\hline & \multirow{3}{*}{$\begin{array}{l}\text { HR } \\
\text { I.0I }\end{array}$} & \multicolumn{2}{|c|}{$95 \% \mathrm{Cl}$} & \multirow{3}{*}{$\begin{array}{l}P \\
0.00 *\end{array}$} & \multirow{3}{*}{$\begin{array}{l}\text { HR } \\
1.00\end{array}$} & \multicolumn{2}{|c|}{$95 \% \mathrm{Cl}$} & \multirow{3}{*}{$\begin{array}{l}P \\
0.09\end{array}$} & \multirow{3}{*}{$\begin{array}{l}\text { HR } \\
1.00\end{array}$} & \multicolumn{2}{|c|}{$95 \% \mathrm{Cl}$} & \multirow{3}{*}{$\begin{array}{l}\boldsymbol{P} \\
0.02 *\end{array}$} \\
\hline & & & & & & & & & & & & \\
\hline & & 1.00 & 1.01 & & & 0.99 & I.0I & & & 1.00 & 1.01 & \\
\hline \multicolumn{13}{|l|}{ Adjusted covariates } \\
\hline SUA & I.0I & 1.00 & 1.01 & $0.00 *$ & 1.00 & 0.99 & 1.01 & 0.56 & 1.00 & 1.00 & 1.01 & $0.01 *$ \\
\hline Age & 1.03 & 1.01 & 1.06 & $0.01 *$ & 1.03 & 1.01 & 1.06 & $0.02 *$ & 1.03 & 1.01 & 1.05 & $0.00 *$ \\
\hline BMI & 0.99 & 0.91 & 1.08 & 0.83 & 1.02 & 0.98 & 1.05 & 0.36 & 1.00 & 0.99 & 1.01 & 0.72 \\
\hline Gender & I & I & I & I & 1 & I & I & 1 & 2.27 & 1.30 & 3.97 & $0.00 *$ \\
\hline Drinking status & 1.13 & 0.62 & 2.06 & 0.69 & 1 & I & I & 1 & 0.88 & 0.51 & 1.51 & 0.65 \\
\hline Smoking status & 1.30 & 0.71 & 2.40 & 0.40 & I & l & I & 1 & 1.05 & 0.59 & 1.85 & 0.87 \\
\hline Rhinitis & 1.77 & 0.17 & 18.77 & 0.64 & I & l & I & I & 1.32 & 0.13 & 13.16 & 0.81 \\
\hline Nasal polyps & 7.59 & 1.33 & 43.31 & $0.02 *$ & I & l & I & I & 8.10 & $\mathrm{I} .54$ & 42.67 & $0.01 *$ \\
\hline Pulmonary infection & 0.22 & 0.02 & 1.95 & 0.17 & 0.82 & 0.10 & 6.85 & 0.85 & 0.31 & 0.07 & 1.42 & 0.13 \\
\hline Pneumonia & 5.05 & 2.02 & 12.62 & $0.00 *$ & 2.79 & 0.98 & 7.95 & $0.05 *$ & 4.21 & 2.10 & 8.45 & $0.00 *$ \\
\hline Bronchitis & 3.81 & 1.46 & 9.93 & $0.01 *$ & 11.14 & 4.67 & 26.56 & $0.00 *$ & 5.96 & 3.09 & 11.48 & $0.00 *$ \\
\hline COPD & 9.21 & 2.90 & 29.31 & $0.00 *$ & 14.39 & 3.97 & 52.09 & $0.00 *$ & 8.83 & 3.74 & 20.85 & $0.00 *$ \\
\hline Bronchiectasis & 1.88 & 0.21 & 16.97 & 0.57 & I & l & I & I & 1.29 & 0.16 & 10.25 & 0.81 \\
\hline
\end{tabular}

Note: $* P<0.05 /$ Invalid data.

Abbreviations: BMI, body mass index; COPD, chronic obstructive pulmonary disease; SUA, serum uric acid. 

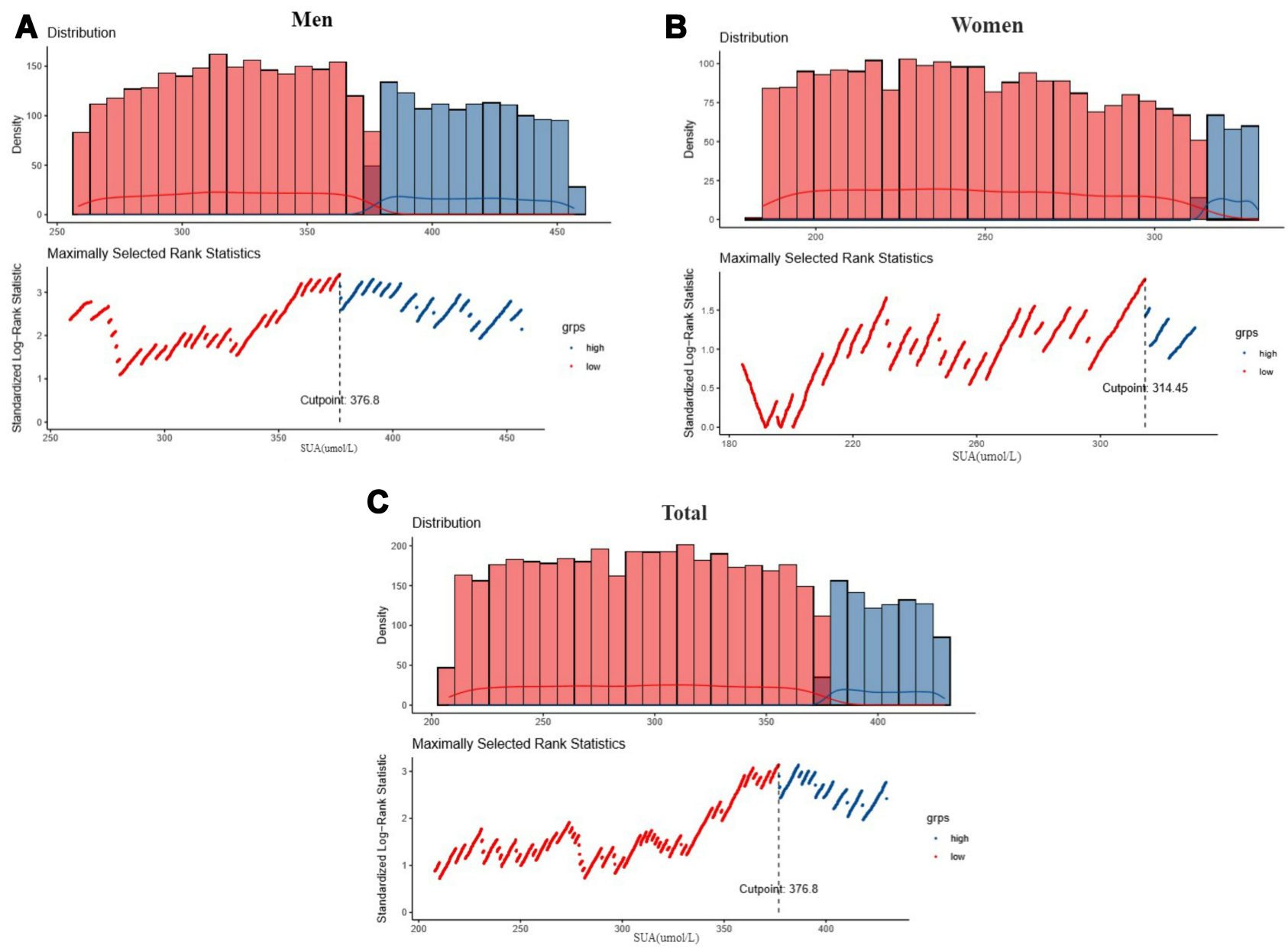

Figure 3 Evaluating the cutoff point of SUA level with maximally selected rank statistics $(P<0.02)$.

necessary to find the cut-off value for men and women separately.

The cut-off value of SUA in men identifying those at higher risk of developing incident asthma was over 376.8umol/L during the follow-up, which commonly was lower than the SUA values related to hyperuricemia. However, in women, a theoretical univariate cut-off of SUA could be identified by the maximally selected rank statistics method, but it was without no independent value in the multivariate Cox proportional hazards model and the Poisson regression model. The cut-off values identified were therefore because of men only in the whole participants.

Several studies have reported a stronger correlation between SUA and asthma. In a retrospective study performed on 217 asthma exacerbation patients, SUA levels increased at the onset of asthma exacerbation and had a negative impact on lung function. ${ }^{16}$ In a large population-based epidemiological study, Fukuhara et al reported that elevated SUA levels may predict the development of airflow limitation risk in COPD and asthma patients. ${ }^{21}$ The result of Abdulnaby et al showed that high SUA had a significant positive correlation with severe asthma and a negative association with spirometric pulmonary functions in hospitalized adolescents and adults with acute asthma. ${ }^{15}$ Besides, Aida et al 's study demonstrated that there were significant inverse correlations between spirometric parameters and SUA levels in adults who participated in an annual health check. ${ }^{22}$ However, other studies have reported conflicting results. A study involving 50 adult Nigerian asthmatic patients, aged 40 to 50 years, demonstrated that the levels of UA were lower in asthmatics than in controls $(P<0.00){ }^{23}$ Furthermore, a casecontrolled prospective study conducted on 219 children aged 1-12 years showed that asthmatic children during exacerbation of their asthma have significantly lower serum levels of UA $(p<0.001) .^{24}$

There were several possible pathophysiological mechanisms that explained the relationship between SUA and 
Table 3 Cox Models for Incident Asthma Using Serum Uric Acid as a Binary Independent Variable

\begin{tabular}{|c|c|c|c|c|c|c|c|c|c|c|c|c|}
\hline \multirow{3}{*}{$\begin{array}{l}\text { Independent Variables } \\
\text { Unadjusted covariates } \\
\text { SUA }\end{array}$} & \multicolumn{4}{|l|}{ Men } & \multicolumn{4}{|c|}{ Women } & \multicolumn{4}{|c|}{ Total } \\
\hline & \multirow{2}{*}{$\begin{array}{l}\text { HR } \\
2.53\end{array}$} & \multicolumn{2}{|c|}{$95 \% \mathrm{Cl}$} & \multirow{2}{*}{$\begin{array}{l}P \\
0.00 *\end{array}$} & \multirow{2}{*}{$\begin{array}{l}\text { HR } \\
2.26\end{array}$} & \multicolumn{2}{|c|}{$95 \% \mathrm{Cl}$} & \multirow{2}{*}{$\begin{array}{l}P \\
0.04^{*}\end{array}$} & \multirow{2}{*}{$\begin{array}{l}\text { HR } \\
2.01\end{array}$} & \multicolumn{2}{|c|}{$95 \% \mathrm{Cl}$} & \multirow{2}{*}{$\begin{array}{l}P \\
0.00 *\end{array}$} \\
\hline & & 1.46 & 4.37 & & & 1.03 & 4.97 & & & 1.30 & 3.11 & \\
\hline \multicolumn{13}{|l|}{ Adjusted covariates } \\
\hline SUA & 3.02 & 1.70 & 5.39 & $0.00 *$ & 1.75 & 0.78 & 3.96 & 0.18 & 2.92 & 1.76 & 4.84 & $0.00 *$ \\
\hline Age & 1.03 & 1.01 & 1.06 & $0.01 *$ & 1.03 & 1.00 & 1.06 & $0.02^{*}$ & 1.03 & 1.01 & 1.05 & $0.00 *$ \\
\hline BMI & 1.00 & 0.92 & 1.08 & 0.91 & 1.02 & 0.98 & 1.05 & 0.35 & 1.00 & 0.99 & 1.01 & 0.66 \\
\hline Gender & l & I & 1 & I & l & l & I & I & 2.11 & 1.22 & 3.64 & $0.01 *$ \\
\hline Drinking status & 1.14 & 0.63 & 2.08 & 0.66 & I & I & I & l & 1.09 & 0.61 & 1.95 & 0.78 \\
\hline Smoking status & 1.31 & 0.71 & $2.4 I$ & 0.39 & l & l & l & I & 1.28 & 0.70 & 2.35 & 0.42 \\
\hline Rhinitis & 1.44 & 0.13 & 15.65 & 0.76 & I & I & l & I & 1.24 & 0.12 & 12.73 & 0.85 \\
\hline Nasal polyps & 8.48 & 1.48 & 48.63 & $0.02 *$ & l & l & l & I & 9.85 & 1.84 & 52.80 & $0.01 *$ \\
\hline Pulmonary infection & 0.16 & 0.02 & 1.54 & 0.11 & 0.85 & 0.11 & 6.95 & 0.88 & 0.22 & 0.05 & 1.10 & 0.07 \\
\hline Pneumonia & 5.33 & 2.12 & 13.38 & $0.00 *$ & 3.02 & 1.08 & 8.43 & $0.03^{*}$ & 4.31 & 2.16 & 8.62 & $0.00 *$ \\
\hline Bronchitis & 4.08 & 1.56 & 10.65 & $0.00^{*}$ & 11.15 & 4.72 & 26.34 & $0.00^{*}$ & 6.29 & 3.28 & 12.09 & $0.00 *$ \\
\hline COPD & 8.45 & 2.67 & 26.71 & $0.00 *$ & 14.10 & 3.99 & 49.86 & $0.00 *$ & 9.83 & 4.17 & 23.19 & $0.00 *$ \\
\hline Bronchiectasis & 2.43 & 0.28 & 20.90 & 0.42 & I & I & l & I & 1.49 & 0.19 & 11.66 & 0.70 \\
\hline
\end{tabular}

Note: $* \mathrm{P}<0.05 /$ Invalid data

Abbreviations: BMI, body mass index; COPD, chronic obstructive pulmonary disease; SUA, serum uric acid.

incident asthma. The oxidant/antioxidant imbalance plays a pivotal role in the lung. UA, an endogenous antioxidant, is highly present in lung tissue. Pulmonary hypoxia resulted in greater purine catabolism leading to an increase in the production of UA, which indicated UA may be a useful marker of lung injury. ${ }^{25}$ In addition, the airway levels of SUA are increased in patients with asthma after allergen exposure during disease exacerbation. UA in respiratory mucosa may play a central role as a sensor of allergen exposure, and may initiate and exacerbate Th2-type immunity in the airways. ${ }^{26}$ In addition, higher blood UA is a protective factor against the pathological decline of lung function in female mice, because of UA significantly suppressed hydrogen peroxide, ${ }^{27}$ which may explain that we have not found that UA is a risk factor for incident asthma in the female population. However, the reason why plausible multivariate cut-off values could be found in men only is not clear. The specific mechanism still needs more biochemical and clinical studies to explore in this respect.

There were some differences in the relationship between covariates and asthma in the Poisson regression model and the Cox proportional hazards model. Combining the results of the two models, we found that gender, nasal polyps, pneumonia, bronchitis, and COPD were associated with an increased risk of asthma in the general population, which was consistent with previous research results. A large crosssectional study of 164,215 participants in Mainland China found that bronchitis, gender, COPD, and allergic pneumonia were risk factors for asthma. ${ }^{28}$ In addition, patients with nasal polyps were more likely to report asthma, ${ }^{29}$ which reflects the substantial interaction between the lower and upper airways and in particular between the underlying aetiological mechanisms of airways pathology.

The strength of this study shown herein is that, to our knowledge, it is the first aimed at finding the cut-off value of SUA for incident asthma in a large population. The limitations are represented by the fact that the measurement of SUA overtime was not included in this study, as some subjects did not participate in a regular checkup; The findings may not be generalizable to all healthy people and only apply for the population at risk. "population at risk" is defined as a population with a high risk of incident asthma, such as people with more asthma-like diseases (nasal polyps, bronchitis, pneumonia, or COPD) $)^{28,30-32}$ and an older population ${ }^{33}$ in this study. Compared with the individuals excluded from this study because of missing SUA, the participants included in our study may have a higher risk of incident asthma. Finally, the genetic context of the association between SUA and asthma will be considered in further research. ${ }^{34}$

In summary, this open cohort study provides evidence that the measurement of the SUA level might provide significant information about incident asthma in men in addition to the evaluation of traditional risk factors in clinical 


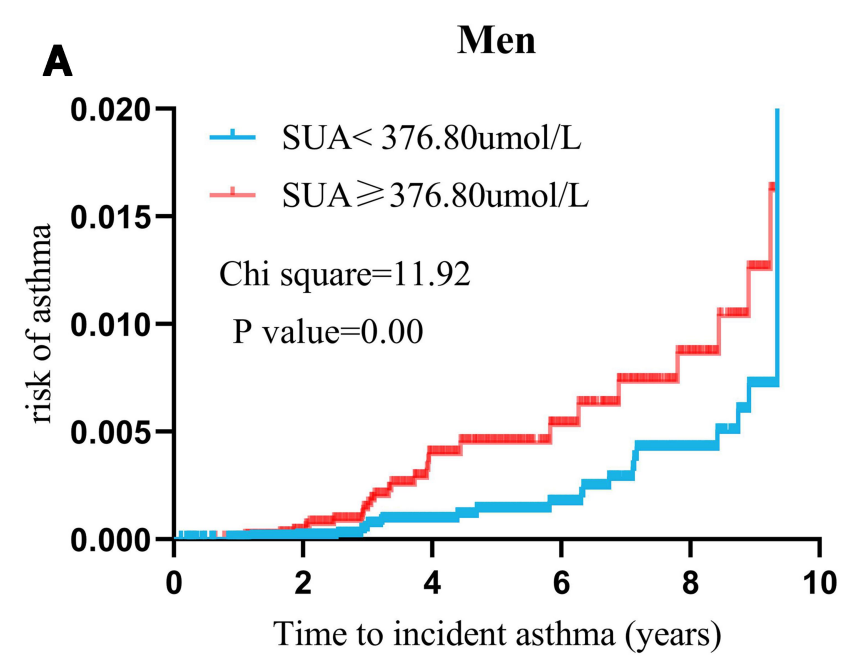

C

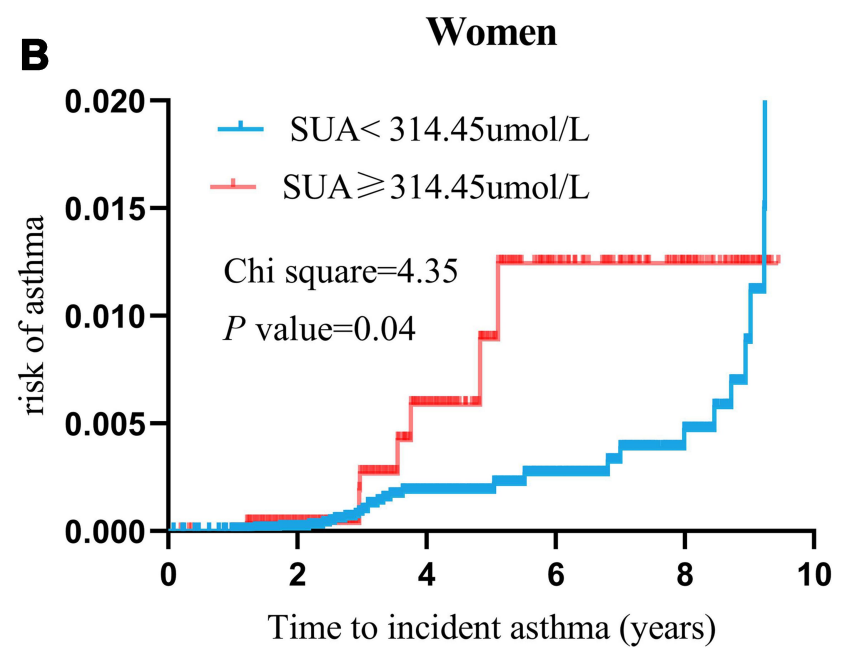

Total

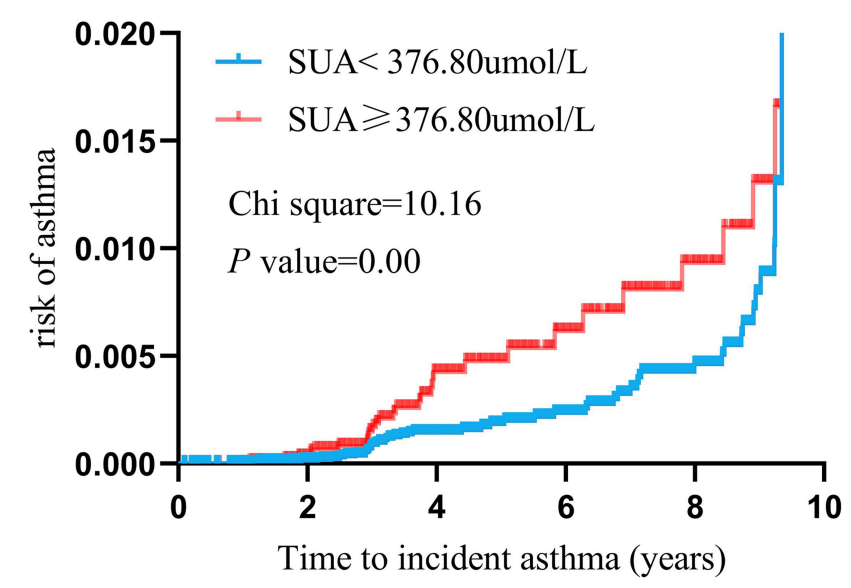

Figure 4 Cumulative hazard function of SUA cutoff points for asthma incidence in men, women and all participants. These risk curves did not adjusted covariates. Redline (upper line) represents SUA $\geq$ cut-off values, and blue line (lower line) represents SUA < cut-off values. (A)The univariate cut-off value of SUA for incident asthma among men was 376.80umol/L; (B) The univariate cut-off value of SUA for incident asthma among women was 3/4.45umol/L; (C) The univariate cut-off value of SUA for incident asthma among total participants was $376.80 \mathrm{umol} / \mathrm{L}$.

practice. Furthermore, high levels of SUA may become a relevant biologic marker of asthma severity in men.

\section{Abbreviations}

$\mathrm{HR}$, hazard ratio; $\mathrm{CI}$, confidence interval; BMI, body mass index; COPD, chronic obstructive pulmonary disease; SUA, serum uric acid; UA, uric acid; IQR, interquartile range.

\section{Author Contributions}

All authors contributed to data analysis, drafting or revising the article, have agreed on the journal to which the article will be submitted, gave final approval of the version to be published, and agree to be accountable for all aspects of the work.

\section{Funding}

This work was supported by the Key Research and Development Program of Shandong Province (Grant No. 2019GSF108198), and the Humanities and Social Sciences Youth Team Project of Shandong University (Grant Nos. IFYT1811, IFYT18036, and IFYT18037). The funding bodies were not involved in the design of the study, the collection, analysis, and interpretation of data and the preparation of the manuscript.

\section{Disclosure}

The authors have declared no conflicts of interest. The authors declare that they have no known competing financial interests or personal relationships that could 
have appeared to influence the work reported in this paper.

\section{References}

1. Vos T, Flaxman AD, Naghavi M, et al. Years lived with disability (YLDs) for 1160 sequelae of 289 diseases and injuries 1990-2010: a systematic analysis for the Global Burden of Disease Study 2010. Lancet. 2012;380(9859):2163-2196. doi:10.1016/S0140-6736(12) 61729-2

2. Loftus PA. Wise SK: epidemiology and economic burden of asthma. Int Forum Allergy Rhinol. 2015;5(Suppl 1):S7-S10. doi:10.1002/ alr.21547

3. Yaghoubi M, Adibi A, Safari A, FitzGerald JM, Sadatsafavi M. The projected economic and health burden of uncontrolled asthma in the United States. Am J Resp Crit Care. 2019;200(9):1102-1112. doi:10.1164/rccm.201901-0016OC

4. Chongmelaxme B, Lee S, Dhippayom T, Saokaew S, Chaiyakunapruk N, Dilokthornsakul P. The effects of telemedicine on asthma control and patients' quality of life in adults: a systematic review and meta-analysis. $J$ Allergy Clin Immunol. 2019;7 (1):199-216.

5. Beasley R, Semprini A. Mitchell EA: risk factors for asthma: is prevention possible? Lancet (London, England). 2015;386 (9998):1075-1085. doi:10.1016/S0140-6736(15)00156-7

6. Horsfall LJ, Nazareth I, Petersen I. Serum uric acid and the risk of respiratory disease: a population-based cohort study. Thorax. 2014;69 (11):1021-1026. doi:10.1136/thoraxjnl-2014-205271

7. Lima WG, Martins-Santos MES, Chaves VE. Uric acid as a modulator of glucose and lipid metabolism. Biochimie. 2015;116:17-23. doi:10.1016/j.biochi.2015.06.025

8. Johnson RJ, Nakagawa T, Jalal D, Sánchez-Lozada LG, Kang D, Ritz E. Uric acid and chronic kidney disease: which is chasing which? Nephrol Dial Transplant. 2013;28(9):2221-2228. doi:10. 1093/ndt/gft029

9. Shiozawa A, Szabo SM, Bolzani A, Cheung A, Choi HK. Serum uric acid and the risk of incident and recurrent gout: a systematic review. J Rheumatol. 2017;44(3):388-396. doi:10.3899/jrheum.160452

10. Holme I, Aastveit AH, Hammar N, Jungner I, Walldius G. Uric acid and risk of myocardial infarction, stroke and congestive heart failure in 417,734 men and women in the Apolipoprotein MOrtality RISk study (AMORIS). J Intern Med. 2009;266(6):558-570. doi:10.1111/ j.1365-2796.2009.02133.x

11. Yuan H, Yu C, Li X, et al. Serum uric acid levels and risk of metabolic syndrome: a dose-response meta-analysis of prospective studies. J Clin Endocrinol Metab. 2015;100(11):4198-4207.

12. Yu K, Chen D, Chen J, et al. Management of gout and hyperuricemia: multidisciplinary consensus in Taiwan. Int $J$ Rheum Dis. 2018;21:772-787.

13. Kool M, Willart MAM, van Nimwegen M, et al. An unexpected role for uric acid as an inducer of $\mathrm{T}$ helper 2 cell immunity to inhaled antigens and inflammatory mediator of allergic asthma. Immunity. 2011;34(4):527-540. doi:10.1016/j.immuni.2011.03.015

14. Martinon F, Pétrilli V, Mayor A, Tardivel A, Tschopp J. Goutassociated uric acid crystals activate the NALP3 inflammasome. Nature. 2006;440(7081):237-241. doi:10.1038/nature04516

15. Abdulnaby NK, Sayed AO, Shalaby NM. Predictive value of serum uric acid in hospitalized adolescents and adults with acute asthma Ther Clin Risk Manag. 2016;12:1701-1708.

16. Li L, Wan C, Wen F. An unexpected role for serum uric acid as a biomarker for severity of asthma exacerbation. Asian Pac J Allergy. 2014;32(1):93-99.
17. Borghi C, Rosei EA, Bardin T, et al. Serum uric acid and the risk of cardiovascular and renal disease. J Hypertens. 2015;33(9):17291741, 1741. doi:10.1097/HJH.0000000000000701

18. Asthma Section, Respiratory Disease Branch Chinese. Guidelines for the prevention and treatment of bronchial asthma (definition, diagnosis, treatment, education and management of bronchial asthma). Chinese Journal of Internal Medicine. 2003;(11):68-73. doi:10.3760/ j.issn:0578-1426.2003.11.028

19. Lausen B, Schumacher M. Maximally selected rank statistics. Biometrics. 1992;48(1):73-85. doi:10.2307/2532740

20. Casiglia E, Tikhonoff V, Virdis A, et al. Serum uric acid and fatal myocardial infarction: detection of prognostic cut-off values: the URRAH (Uric Acid Right for Heart Health) study. $J$ Hypertens. 2020;38(3):412-419. doi:10.1097/HJH.0000000000002287

21. Fukuhara A, Saito J, Sato S, et al. The association between risk of airflow limitation and serum uric acid measured at medical health check-ups. Int J Chronic Obstr. 2017;12:1213-1219.

22. Aida Y, Shibata Y, Osaka D, et al. The relationship between serum uric acid and spirometric values in participants in a health check: the Takahata study. Int J Med Sci. 2011;8(6):470-478. doi:10.7150/ijms.8.470

23. Anetor JI, Ajose OA, Ige O, Oyeleye AO, Ojo PO. Antioxidant status of adult Nigerian asthmatics: implications for prognosis. Nutr Health. 2003;17(3):221-229. doi:10.1177/026010600301700305

24. Al-Abdulla NO, Al Naama LM, Hassan MK. Antioxidant status in acute asthmatic attack in children. J Pak Med Assoc. 2010;60 (12):1023-1027.

25. Elsayed NM, Nakashima JM, Postlethwait EM. Measurement of uric acid as a marker of oxygen tension in the lung. Arch Biochem Biophys. 1993;302(1):228-232.

26. Hara K, Iijima K, Elias MK, et al. Airway uric acid is a sensor of inhaled protease allergens and initiates type 2 immune responses in respiratory mucosa. J Immunol. 2014;192(9):4032-4042. doi:10. 4049/jimmunol.1400110

27. Fujikawa H, Sakamoto Y, Masuda N, et al. Higher blood uric acid in female humans and mice as a protective factor against pathophysiological decline of lung function. Antioxidants (Basel, Switzerland). 2020;9:5.

28. Lin J, Wang W, Chen P, et al. Prevalence and risk factors of asthma in mainland China: the CARE study. Resp Med. 2018;137:48-54. doi:10.1016/j.rmed.2018.02.010

29. Philpott CM, Erskine S, Hopkins C, et al. Prevalence of asthma, aspirin sensitivity and allergy in chronic rhinosinusitis: data from the UK National Chronic Rhinosinusitis Epidemiology Study. Resp Res. 2018;19(1):129. doi:10.1186/s12931-018-0823-y

30. Bai C, Jiang D, Wang L, Xue F, Chen O. A high blood eosinophil count may be a risk factor for incident asthma in population at risk. Resp Med. 2019;151:59-65. doi:10.1016/j.rmed.2019. 03.016

31. Huang K, Yang T, Xu J, et al. Prevalence, risk factors, and management of asthma in China: a national cross-sectional study. Lancet (London, England). 2019;394(10196):407-418. doi:10.1016/S01406736(19)31147-X

32. Toskala E, Kennedy DW. Asthma risk factors. Int Forum Allergy Rh. 2015;5 Suppl 1(Supp11):S11-S16. doi:10.1002/alr.21557

33. Braman SS. Asthma in the Elderly. Clin Geriatr Med. 2017;33 (4):523-537. doi:10.1016/j.cger.2017.06.005

34. Li X, Meng X, Spiliopoulou A, et al. MR-PheWAS: exploring the causal effect of SUA level on multiple disease outcomes by using genetic instruments in UK Biobank. Ann Rheum Dis. 2018;77:1039-1047. 


\section{Publish your work in this journal}

Risk Management and Healthcare Policy is an international, peerreviewed, open access journal focusing on all aspects of public health, policy, and preventative measures to promote good health and improve morbidity and mortality in the population. The journal welcomes submitted papers covering original research, basic science, clinical \& epidemiological studies, reviews and evaluations, guidelines, expert opinion and commentary, case reports and extended reports. The manuscript management system is completely online and includes a very quick and fair peer-review system, which is all easy to use. Visit http://www.dovepress.com/testimonials.php to read real quotes from published authors.

Submit your manuscript here: https://www.dovepress.com/risk-management-and-healthcare-policy-journal 